\title{
Non-opioid analgesia improves pain relief and decreases sedation after gastric bypass surgery
}

\author{
[Un traitement non opioïde améliore l'analgésie et provoque moins de sédation
}

après un pontage gastrique]

James M. Feld MD, Charles E. Laurito MD, Mihail Beckerman MD, Joseph Vincent MD, William E. Hoffman PhD

Purpose: Several non-opioid drugs have been shown to provide analgesia during and after surgery. We compared sevoflurane anesthesia with fentanyl analgesia to sevoflurane and non-opioid drug treatment for gastric bypass surgery and recovery.

Methods: Thirty obese patients (body mass index $>50 \mathrm{~kg} \cdot \mathrm{m}^{-2}$ ) undergoing gastric bypass were randomized to receive sevoflurane anesthesia with either fentanyl or a non-opioid regimen including ketorolac, clonidine, lidocaine, ketamine, magnesium sulfate, and methylprednisolone. Morphine use by patient-controlled analgesia (PCA) pump and pain score measured by visual analogue scale were determined in the postanesthesia care unit (PACU) and for the first 16 hr after surgery. Sedation was evaluated in the PACU. Investigators assessing patient outcomes were blinded to the study group.

Results: Fentanyl treated patients were more sedated in the PACU compared to the non-opioid group. Non-opioid treated patients required $5.2 \pm 2.6 \mathrm{mg} \cdot \mathrm{hr}^{-1}$ morphine by PCA during their stay in the PACU while patients anesthetized with fentanyl used $7.8 \pm 3.3$ $\mathrm{mg} \cdot \mathrm{hr}^{-1}(P<0.05)$. Fentanyl and non-opioid treated patients showed no difference in pain score one or $16 \mathrm{hr}$ after surgery.

Conclusion: Our results show that non-opioid analgesia produced pain relief and less sedation during recovery from gastric bypass surgery compared to fentanyl.

Objectif : On reconnaît à certains médicaments non-opiö̈des des qualités analgésiques pendant et après une intervention chirurgicale. Nous avons comparé l'anesthésie au sévoflurane accompagnée d'une analgésie, soit avec fentanyl, soit avec un non opioïde pendant et après le pontage gastrique.

Méthode : Trente patients obèses (index de masse corporelle $>50$ $\mathrm{kg} \cdot \mathrm{m}^{-2}$ ) devant subir un pontage gastrique ont été répartis au hasard et ont reçu une anesthésie au sévoflurane avec, soit du fentanyl, soit un schéma posologique comportant kétorolac, clonidine, lidocaïne, kétamine, sulfate de magnésium et méthylprednisolone. L'usage de morphine par une pompe d'analgésie auto-contrôlée (AAC) et le score de douleur par l'échelle visuelle analogique ont été enregistrés à la salle de réveil (SDR) et pendant les seize premières heures après l'opération. La sédation a été évaluée à la SDR. L'évaluation des patients a été faite par des chercheurs impartiaux.

Résultats : La sédation, notée à la SDR, était plus importante chez les patients traités au fentanyl, comparés à ceux traités avec un médicament non-opiö̈de. Les patients traités aux non-opiö̈des ont demandé 5,2 \pm 2,6 $\mathrm{mg} \cdot \mathrm{h}^{-1}$ de morphine en AAC pendant leur séjour en SDR tandis que les patients anesthésiés au fentanyl en ont utilisé 7,8 $\pm 3,3 \mathrm{mg} \cdot \mathrm{h}^{-1}(P<0,05)$. Les scores de douleurs des patients des deux groupes n'ont présenté aucune différence, une ou 16 h après l'opération.

Conclusion : L'analgésie avec des non opioïdes, comparé au fentanyl, a mieux soulagé la douleur et provoqué moins de sédation pendant la récupération qui suit un pontage gastrique.

$\mathrm{T}$ HE body mass index (BMI), calculated as the weight in kilograms divided by the height in metres squared, has been used in clinical and epidemiological studies as a predictor of health risk. ${ }^{1} \mathrm{~A}$ BMI of $25 \mathrm{~kg} \cdot \mathrm{m}^{-2}$ is considered normal, > $30 \mathrm{~kg} \cdot \mathrm{m}^{-2}$ obese, $>35 \mathrm{~kg} \cdot \mathrm{m}^{-2}$ morbidly obese and $>55 \mathrm{~kg} \cdot \mathrm{m}^{-2}$ super morbidly obese. Respiratory problems are associated with morbid obesity, including obstructive apnea during sleep, decreased functional residual capacity and lung compliance and increased work of breathing. ${ }^{2,3}$ Obese patients may be sensitive to the respiratory depressant effect of opioid analgesic drugs and more likely to require postoperative ventilation to avoid hypoxic episodes. ${ }^{4}$

From the Department of Anesthesiology, University of Illinois at Chicago, Chicago, Illinois, USA.

Address correspondence to: Dr. William E. Hoffman, Department of Anesthesiology, M/C 515,

University of Illinois at Chicago, 1740 West Taylor Street, Chicago, Illinois 60612, USA. Phone: 312-996-4018; Fax: 312-996-4019;

E-mail: whoffman@uic.edu

Accepted for publication October 22, 2002.

Revision accepted December 13, 2002. 
It has been recommended that opioid drugs be avoided for analgesia in the morbidly obese patient because of the risk of respiratory depression. ${ }^{5}$ This requires that alternative drugs be used in place of opioids to provide analgesia during surgery. Several drugs, including clonidine, ketamine, magnesium, lidocaine, ketorolac, and steroids have all been shown to be analgesic. ${ }^{6-11}$ Combining these drugs may potentiate analgesia by separate actions and decrease the risk of side effects by lowering the effective dose for each agent. ${ }^{12,13}$ The purpose of this study was to compare fentanyl analgesia with a combination of non-opioid drugs for gastric bypass surgery. Anesthesia was provided with sevoflurane in both groups and postoperative scores of pain, sedation, morphine use by patient-controlled analgesia (PCA), and the requirement for intubation in the postanesthesia care unit (PACU) were measured.

\section{Material and methods}

This study received Institutional review board approval for clinical research. Thirty obese patients $\left(\mathrm{BMI}>50 \mathrm{~kg} \cdot \mathrm{m}^{-2}\right)$ undergoing gastric bypass were recruited and provided an informed signed consent. Gastric bypass was performed by open laparotomy and dissection of the stomach with reanastomosis of the small intestine. Exclusion criteria were: age $<18 \mathrm{yr}$, a positive pregnancy test, patients with a history of drug abuse or who were dependent on opioid drugs, patients with chronic pain, or patients with severe cardiac, pulmonary, liver or neurological disease.

Patients were randomized using a randomization table to receive either sevoflurane and fentanyl or the non-opioid drug regimen for intraoperative anesthesia. The patient and the investigator scoring patient outcome after surgery were blinded to the anesthetic treatment. Patients in the fentanyl group received sevoflurane anesthesia supplemented with intermittent boluses of $50 \mu \mathrm{g}$ fentanyl up to a total dose not to exceed $6 \mu \mathrm{g} \cdot \mathrm{kg}^{-1}$ of ideal body weight. Ideal body weight was calculated in men as: ideal body weight (in kilograms) $=50 \pm 2.3 \mathrm{~kg}$ per $2.5 \mathrm{~cm}$ over $160 \mathrm{~cm}$, women: ideal body weight (in kilograms) $=45.5 \pm 2.3$ $\mathrm{kg}$ per $2.5 \mathrm{~cm}$ over $160 \mathrm{~cm}$.

Patients in the non-opioid group were ventilated with sevoflurane and anesthesia was supplemented with ketorolac, $30 \mathrm{mg} i v$ given at the beginning and end of the case, clonidine, 300-500 $\mu \mathrm{g}$ iv starting within the first hour of anesthesia as tolerated for maintenance of blood pressure, lidocaine, $100 \mathrm{mg}$ bolus given during induction of anesthesia followed by $4 \mathrm{mg} \cdot \mathrm{min}^{-1}$ for the first hour, $3 \mathrm{mg} \cdot \mathrm{min}^{-1}$ for the second hour and $2 \mathrm{mg} \cdot \mathrm{min}^{-1}$ until the end of the case, ketamine, $0.17 \mathrm{mg} \cdot \mathrm{kg}^{-1} \cdot \mathrm{hr}^{-1}$ with a maximum dose of $1 \mathrm{mg} \cdot \mathrm{kg}^{-1}$ given with the iv saline fluid maintenance infusion, magnesium sulfate, $80 \mathrm{mg} \cdot \mathrm{kg}^{-1}$ total dose given in the $i v$ saline fluid maintenance infusion during the case, and methylprednisolone, $60 \mathrm{mg}$ given as an $i v$ bolus in the holding area before the start of surgery. Doses were calculated according to ideal body weight. Brain electrical activity (Bispectral Index, Aspect Biomedical, Natick, MA, USA) was maintained at 40-60 during surgery in both groups.

Patient age, height, weight and gender were obtained from the preanesthetic record. Total fentanyl dose and duration of anesthesia were obtained from the anesthetic record. Systolic, diastolic and mean blood pressures, heart rate, and end-tidal sevoflurane concentration were determined every five minutes during anesthesia.

At the end of surgery, extubation was performed when the patient was able to follow commands, there was recovery from muscle relaxation as indicated by a full train-of-four, end-tidal carbon dioxide pressure was less than $45 \mathrm{mmHg}$ with a respiratory frequency less than $25 \cdot \mathrm{min}^{-1}$, and arterial oxygen saturation was $>95 \%$ with an inspired oxygen concentration of $50 \%$. In the PACU, sedation level was scored by the investigator every hour using the following scale: $0=$ alert, $1=$ relaxed, $2=$ sedated, $3=$ asleep, arousable, $4=$ not arousable. Total morphine use by PCA pump was determined in the PACU and for the first $16 \mathrm{hr}$ after surgery. Pain level and patient satisfaction were measured by visual analogue scale (VAS) one hour and 16 hr after surgery. The VAS was rated from low to high pain or satisfaction from 0-100 mm. Systolic and diastolic blood pressures, heart rate and arterial oxygen saturation, determined by pulse oximeter, were recorded every $15 \mathrm{~min}$. Oxygen supplementation was given by mask as needed. Arterial oxygen saturation was measured every $15 \mathrm{~min}$ in the PACU.

\section{Statistics}

Data are reported as mean \pm SD for parametric data or median with a $25 \%$ and a $75 \%$ range for non-parametric data. Blood pressure, heart rate, pain VAS, and satisfaction VAS were compared between groups over time using a two-way repeated measures analysis of variance. Sevoflurane concentration during anesthesia was compared between groups using a rank order analysis of variance. Non-repeated parametric data were compared between groups using an unpaired t test. If data failed requirements for parametric analysis including normality and equal variance then non-parametric tests were used for comparison between groups. Gender data were analyzed by a test of proportions. 


\section{Results}

Patient demographics are shown in Table I. There was no difference in age, weight, BMI or duration of anesthesia for the fentanyl and non-opioid treatment groups. Fentanyl anesthetized patients received an average of $331 \pm 65 \mu \mathrm{g}$ fentanyl during anesthesia.

Average duration of anesthesia was $3.3 \mathrm{hr}$ in both groups. During anesthesia, mean arterial pressure (MAP) was significantly lower in non-opioid $(73 \pm 6 \mathrm{mmHg})$ compared to fentanyl treated patients $(80 \pm 7 \mathrm{mmHg}, P$ $<0.05)$. Less end-tidal sevoflurane was required to maintain anesthesia in non-opioid (median $=1.0 \%, 25 \%$ range $=1.0 \%, 75 \%$ range $=1.5 \%)$ compared to fentanyl treated patients $($ median $=1.5 \%, 25 \%$ range $=1.4 \%, 75 \%$ range $=$ $2.0 \%)$ during surgery $(P<0.001)$.

The median time in the PACU was two hours in both treatment groups. In the PACU, the non-opioid group was less sedated compared to the fentanyl group (Table II). There was no difference in pain scores measured at one hour and $16 \mathrm{hr}$ between the two groups. Morphine use in the PACU was $5.2 \pm 2.6$ $\mathrm{mg} \cdot \mathrm{hr}^{-1}$ in the non-opioid group and $7.8 \pm 3.3$ $\mathrm{mg} \cdot \mathrm{hr}^{-1}$ in the fentanyl group $(P<0.05)$. Total morphine use $16 \mathrm{hr}$ after surgery was $41.3 \pm 18.0 \mathrm{mg}$ and $45.1 \pm 25.3 \mathrm{mg}$ in the non-opioid and fentanyl groups respectively $(P>0.05)$.

Satisfaction level, analyzed by analysis of variance, was higher in non-opioid anesthetized patients compared to fentanyl anesthetized patients over both the
PACU and $16 \mathrm{hr}$ postsurgery measurements $(P<$ $0.05)$, but not at either time period alone. Two of the 15 patients in the fentanyl anesthetized group remained intubated during their stay in the PACU compared to no patients in the non-opioid group. Arterial oxygen saturation was $>95 \%$ in all patients in the PACU, with no difference between the groups.

\section{Discussion}

In this study we found that a non-opioid drug combination (ketorolac, clonidine, lidocaine, ketamine, magnesium sulfate and methylprednisolone) produced adequate anesthesia with less cardiovascular stimulation compared to fentanyl anesthesia during gastric bypass surgery. MAP was significantly lower in nonopioid compared to fentanyl treated patients and endtidal sevoflurane required to maintain anesthesia was lower in non-opioid treated patients. In the PACU, non-opioid treated patients were less sedated, required less morphine by PCA and had similar pain scores compared to fentanyl anesthetized patients. It was necessary to maintain intubation and ventilation in two of the 15 fentanyl anesthetized patients in the PACU due to inadequate respiration compared to zero of 15 for the non-opioid drug treatment. These results are consistent with reports that preemptive analgesia and multi-modal drug strategies are effective in reducing surgical and postoperative pain and improving outcome for the patient. ${ }^{14-16}$ These drugs

TABLE I Patient demographics, body mass index and duration of anesthesia in patients anesthetized with fentanyl or non-opioid anesthetic

\begin{tabular}{llllllll}
\hline Group & $n$ & Age $(\mathrm{yr})$ & Gender $(\mathrm{m} / \mathrm{f})$ & Weight $(\mathrm{kg})$ & Height $(\mathrm{cm})$ & $\begin{array}{l}\text { Body mass index } \\
\left(\mathrm{kg} \cdot \mathrm{m}^{-2}\right)\end{array}$ & $\begin{array}{l}\text { Duration } \\
\text { anesthesia }(\mathrm{br})\end{array}$ \\
\hline Fentanyl & 15 & $41 \pm 7$ & $3 / 12$ & $146 \pm 36$ & $167 \pm 10$ & $54 \pm 12$ & $3.3 \pm 0.4$ \\
Non-opioid & 15 & $44 \pm 8$ & $5 / 10$ & $151 \pm 26$ & $167 \pm 8$ & $56 \pm 9$ & $3.3 \pm 0.4$ \\
\hline
\end{tabular}

Mean \pm SD for parametric data; no statistical differences between groups.

TABLE II Patient sedation, pain, satisfaction scores and morphine used by patient controlled analgesia pump during recovery and 16 hr after the end of surgery

\begin{tabular}{|c|c|c|c|c|c|c|}
\hline Measure & Location & Time $(h r)$ & Type of score & Fentanyl & Non-opioid & $P$ \\
\hline Sedation & PACU & 1 & median & $2(2,3)$ & $1(1,2)$ & 0.01 \\
\hline Pain VAS & PACU & 1 & mean & $61 \pm 21$ & $53 \pm 26$ & 0.80 \\
\hline Satisfaction VAS & PACU & 1 & mean & $82 \pm 21$ & $90 \pm 8$ & 0.27 \\
\hline PACU morphine (mg) & PACU & per hr & mean & $7.8 \pm 3.3$ & $5.2 \pm 2.6$ & 0.04 \\
\hline Pain VAS & Floor & 16 & mean & $55 \pm 22$ & $54 \pm 29$ & 0.97 \\
\hline Satisfaction VAS & Floor & 16 & mean & $84 \pm 22$ & $95 \pm 4$ & 0.07 \\
\hline Total morphine (mg) & Floor & 16 & mean & $41.3 \pm 18.0$ & $43.1 \pm 25.3$ & 0.71 \\
\hline
\end{tabular}

PACU $=$ postanesthesia care unit; Median $=25 \%$ and $75 \%$ range for non-parametric data; or mean \pm SD for parametric data; PACU morphine $=$ morphine given by patient controlled analgesia in PACU, calculated per hour; Floor indicates patient was transported from the PACU; VAS = visual analogue scale. 
may potentiate analgesia in the obese patient without producing excessive sedation and respiratory depression during recovery from anesthesia.

Ketamine is a unique anesthetic that may be best utilized as an analgesic adjuvant during anesthesia. ${ }^{17}$ In higher doses ketamine has undesirable side effects, including cardiovascular and metabolic stimulation and nightmares. ${ }^{6,18}$ However, low dose ketamine has less frequent incidence of adverse events and can obviate respiratory depression produced by opioids and produce opioid sparing for postoperative analgesia. ${ }^{10,19,20}$ This is consistent with the results of this study. It has been reported that fentanyl can activate N-methyl-Daspartate (NMDA) mediated pain processes, enhancing pain sensitivity, and that this effect is reversed by ketamine pretreatment. ${ }^{21,22}$ In addition to possible analgesic and opioid sparing effects, ketamine has local anesthetic and anti-inflammatory properties. ${ }^{23}$ However, the clinical significance of ketamine mediated analgesia is controversial and there is concern for the cognitive and cardiovascular side effects of the drug.

The use of clonidine with ketamine has been recommended because of the ability of $\alpha_{2}$-agonists to inhibit ketamine mediated sympathetic, cardiovascular and metabolic stimulations, nightmares and other undesirable side effects. ${ }^{12,18,24}$ Low dose clonidine is also reported to prolong postoperative analgesia with no clinically relevant side effects. ${ }^{9}$ Clonidine may act as a central or peripheral sympatholytic agent, resolving sympathetically mediated pain. ${ }^{25}$ In lower doses as used here, the sedative and hypotensive effects of clonidine are attenuated and act to offset the stimulating effects of ketamine.

In addition to ketamine, magnesium is reported to enhance analgesia by blocking the NMDA receptor. ${ }^{13}$ Magnesium also has properties as a sympatholytic and has been promoted as a safe component for balanced general anesthesia. ${ }^{8}$ Although others reported that intraoperative magnesium treatment did not enhance postoperative analgesia, they did observe an inverse relationship between cerebrospinal fluid magnesium levels and postoperative analgesic consumption. ${ }^{26}$ The ability of magnesium and ketamine to inhibit NMDA receptor activity by separate mechanisms may explain why combinations of the drugs are more effective analgesics than either compound alone. ${ }^{13}$

The ability of lidocaine to improve bowel recovery after intra-abdominal surgery, decrease postoperative pain and decrease the hospital stay of patients undergoing abdominal surgery has been shown repeatedly. ${ }^{7,27,28}$ In part, the ameliorative action of lidocaine may be mediated by its ability to inhibit cytokine activity and inflammation in the gut..$^{29,30}$ Lidocaine significantly inhibits gut fluid losses and colitis when administered topically or intravenously, perhaps by inhibition of intrinsic or extrinsic nerves in the gut wall. ${ }^{31,32}$ Lidocaine is reported to have significant analgesic effects that are distinct from that produced by morphine. ${ }^{33}$ It has been suggested that this analgesic effect of lidocaine may be important in its ability to decrease the requirement for inhalation anesthetics. ${ }^{34}$

Ketorolac is a non-steroidal anti-inflammatory drug that has been used to inhibit the inflammatory response to surgical trauma and improve postoperative analgesia. ${ }^{17}$ In addition, ketorolac was associated with decreased incidence of postoperative nausea and vomiting and provided an earlier discharge compared to patients receiving opioid drugs. ${ }^{35}$ Ketorolac provided similar postoperative pain relief to that of fentanyl and produced less nausea and sedation and an earlier return of bowel function after ambulatory surgery. ${ }^{36}$ Compared to morphine, ketorolac-induced analgesia develops more slowly but is longer lasting. ${ }^{37}$ This suggests an important role for ketorolac in the postoperative period for pain management.

Analgesic effects have been reported for corticosteroids after general surgery and back surgery, ${ }^{38,39}$ but these results are controversial. ${ }^{40}$ Intramuscular betamethasone $(12 \mathrm{mg})$, given before the start of ambulatory surgery for foot and hemorrhoid procedures, significantly reduced postoperative pain and nausea compared to a placebo. ${ }^{41}$ The use of perioperative opioids and local anesthetics were minimized in that study to reveal differences in postoperative analgesia. A significant analgesic effect of the steroid was revealed only after three to four hours postoperatively, perhaps related to a delayed effect of protein mediators. ${ }^{41}$ These results suggest that corticosteroids may reduce postoperative pain and nausea when given at the start of surgery.

Epidural analgesia was considered as another alternative to perioperative narcotics for gastric bypass surgery. While this is possible, we found that placement of epidural catheters was technically difficult and they were often displaced within the first $24 \mathrm{hr}$ (unpublished results). The difficulties with epidural placement is consistent with the literature ${ }^{42}$ and prompted our search for an anesthetic drug regimen that could replace the use of narcotics.

The hypothesis of this study was that anesthetic adjuvants that decrease pain by mechanisms separate from opioids could produce analgesia in lower doses when given together, producing less side effects and more rapid recovery compared to fentanyl. Although the non-opioid treatment decreased sedation during recovery from anesthesia and reduced morphine 
requirements in the PACU, it is unclear how each of the treatment compounds contributed to this effect. In contrast, fentanyl anesthesia may produce postoperative hyperalgesia and attenuate the effectiveness of morphine to relieve pain in the postoperative period. ${ }^{19}$ The non-opioid treatment in this study produced analgesia with stable blood pressure and heart rate during surgery and a rapid recovery. This is an advantage compared to fentanyl for gastric bypass surgery in patients that are at risk for respiratory depression.

\section{References}

1 Adams JP, Murphy PG. Obesity in anaesthesia and intensive care. Br J Anaesth 2000; 85: 91-108.

2 Biring MS, Lewis MI, Liu JI, Mohsenifar Z. Pulmonary physiologic changes of morbid obesity. Am J Med Sci 1999; 318: 293-7.

3 Pelosi P, Croci M, Ravagnan I, et al. The effects of body mass on lung volumes, respiratory mechanics, and gas exchange during general anesthesia. Anesth Analg 1998; 87: 645-60.

4 Rawal N, Sjostrand U, Christofferson E, Dahlstrom B, Arvill A, Rydman H. Comparison of intramuscular and epidural morphine for postoperative analgesia in the grossly obese. Influence of postoperative ambulation and pulmonary function. Anesth Analg 1984; 63: 583-92.

5 VanDercar DH, Martinez AP, De Lisser EA. Sleep apnea syndromes: a potential contraindication for patient-controlled analgesia. Anesthesiology 1991; 74: 623-4.

6 White PF. The role of non-opioid analgesic techniques in the management of pain after ambulatory surgery. Anesth Analg 2002; 94: 577-85.

7 Groudine SB, Fisher AG, Kaufman RP Jr, et al. Intravenous lidocaine speeds the return of bowel function, decreases postoperative pain, and shortens hospital stay in patients undergoing radical retropubic prostatectomy. Anesth Analg 1998; 86: 235-9.

8 Schulz-Stubner S, Wettmann G, Reyle-Hahn SM, Rossaint R. Magnesium as part of balanced general anaesthesia with propofol, remifentanil and mivacurium: a double-blind randomized prospective study in 50 patients. Eur J Anaesthesiol 2001; 18: 723-9.

9 Casati A, Magistris L, Fanelli G, et al. Small-dose clonidine prolongs postoperative analgesia after sciaticfemoral nerve block with $0.75 \%$ ropivacaine for foot surgery. Anesth Analg 2000; 91: 388-92.

10 Adriaenssens G, Vermeyen KM, Hoffmann VLH, Mertens E, Adriaensen HF. Postoperative analgesia with i.v. patient-controlled morphine: effect of adding ketamine. Br J Anaesth 1999; 83: 393-6.

11 Chow GK, Fabrizio MD, Steer T, et al. Prospective dou- ble-blind study of effect of ketorolac administration after laparoscopic urologic surgery. J Endourol 2001; 15: $171-4$.

12 Levanen J, Makela ML, Scheinin H. Dexmedetomidine premedication attenuates ketamine-induced cardiostimulatory effects and postanesthetic delirium.

Anesthesiology 1995; 82: 1117-25.

13 Liu HT, Hollmann MW, Liu WH, Hoenemann CW, Durieux ME. Modulation of NMDA receptor function by ketamine and magnesium: part I. Anesth Analg 2001; 92: 1173-81.

$14 \mathrm{Katz}$ J. Pre-emptive analgesia: importance of timing. Can J Anesth 2001; 48: 105-14.

15 Kehlet H, Wilmore DW. Multimodal strategies to improve surgical outcome. Am J Surg 2002; 183: 630-41.

16 Wilder-Smith $O H$. Pre-emptive analgesia and surgical pain. Prog Brain Res 2000; 129: 505-24.

17 White PF, Way WL, Trevor AJ. Ketamine - its pharmacology and therapeutic uses. Anesthesiology 1982; 56: 119-36.

18 Taittonen MT, Kirvela OA, Aantaa R, Kanto JH. The effect of clonidine or midazolam premedication on perioperative responses during ketamine anesthesia. Anesth Analg 1998; 87: 161-7.

19 Mortero RF, Clark LD, Tolan MM, Metz RJ, Tsueda K, Sheppard $R A$. The effects of small-dose ketamine on propofol sedation: respiration, postoperative mood, perception, cognition, and pain. Anesth Analg 2001; 92: 1465-9.

20 Menigaux C, Fletcher D, Dupont X, Guignard B, Guirimand F, Chauvin M. The benefits of intraoperative small-dose ketamine on postoperative pain after anterior cruciate ligament repair. Anesth Analg 2000; 90: 129-35.

21 Celerier E, Rivat C, Jun $\Upsilon$, et al. Long-lasting hyperalgesia induced by fentanyl in rats. Anesthesiology 2000; 92: 465-72.

22 Laulin JP, Maurette P, Corcuff JB, Rivat C, Chauvin $M$, Simonnet $G$. The role of ketamine in preventing fentanyl-induced hyperalgesia and subsequent acute morphine tolerance. Anesth Analg 2002; 94: 1263-9.

23 Hirota K, Zsigmond EK, Matsuki A, Rabito SF. Topical ketamine inhibits albumin extravasation in chemical peritonitis in rats. Acta Anaesthesiol Scand 1995; 39: 174-8.

24 Handa F, Tanaka M, Nichikawa T, Toyooka H. Effects of oral clonidine premedication on side effects of intravenous ketamine anesthesia: a randomized, doubleblind, placebo-controlled study. J Clin Anesth 2000; 12: 19-24.

25 Kamibayashi T, Maze $M$. Clinical uses of $\alpha_{2}$-adrenergic agonists. Anesthesiology 2000; 93: 1345-9. 
26 Ko SH, Lim HR, Kim DC, Han YJ, Choe H, Song HS. Magnesium sulfate does not reduce postoperative analgesic requirements. Anesthesiology 2001; 95: 640-6.

27 de Clive-Lowe SG, Desmond J, North J. Intravenous lignocaine anaesthesia. Anaesthesia 1958; 13: 139-46.

28 Cassuto J, Wallin G, Hogstrom S, Faxen A, Rimback G. Inhibition of postoperative pain by continuous lowdose intravenous infusion of lidocaine. Anesth Analg 1985; 64: 971-4.

29 Taniguchi S, Shibata K, Yamamoto K, Mizukoshi , Kobayashi T. Effects of lidocaine administration on hemodynamics and cytokine responses to endotoxemia in rabbits. Crit Care Med 2000; 28: 755-9.

30 Hollmann MW, Durieux ME. Local anesthetics and the inflammatory response. A new therapeutic indication? Anesthesiology 2000; 93: 858-75.

31 McCafferty DM, Sharkey KA, Wallace JL. Beneficial effects of local or systemic lidocaine in experimental colitis. Am J Physiol 1994; 266: G560-7.

32 Nellgard P, Jonsson A, Bojo L, Tarnow P, Cassuto J. Small-bowel obstruction and the effects of lidocaine, atropine and hexamethonium on inflammation and fluid losses. Acta Anaesthesiol Scand 1996; 40: 287-92.

33 Wu CL, Tella P, Staats PS, et al. Analgesic effects of intravenous lidocaine and morphine on postamputation pain. Anesthesiology 2002; 96: 841-8.

34 Himes RS Jr, DiFaxio CA, Burney RG. Effects of lidocaine on the anesthetic requirements for nitrous oxide and halothane. Anesthesiology 1977; 47: 437-40.

35 Watcha MF, Jones MB, Lagueruela RG, Schweiger C, White PF. Comparison of ketorolac and morphine as adjuvants during pediatric surgery. Anesthesiology 1992; 76: 368-72.

36 Ding $\Upsilon$, White PF. Comparative effects of ketorolac, dezocine, and fentanyl as adjuvants during outpatient anesthesia. Anesth Analg 1992; 75: 566-71.

37 Maunuksela EL, Kokki H, Bullingham RE. Comparison of $i v$ ketorolac with morphine for postoperative pain in children. Clin Pharmacol Ther 1992; 52: 436-43.

38 Schulze S, Moller IW, Bang U, Rye B, Keblet H. Effect of combined prednisolone, epidural analgesia and indomethacin on pain, systemic response and convalescence after cholecystectomy. Acta Chir Scand 1990; 156: 203-9.

39 Glasser RS, Knego RS, Delashaw JB, Fessler RG. The perioperative use of corticosteroids and bupivacaine in the management of lumbar disc disease. J Neurosurg 1993; 78: 383-7.

40 Ohlms LA, Wilder RT, Weston B. Use of intraoperative corticosteroids in pediatric tonsillectomy. Arch Otolaryngol Head Neck Surg 1995; 121: 737-42.

41 Aasboe V, Raeder JC, Groegaard B. Betamethasone reduces postoperative pain and nausea after ambulatory surgery. Anesth Analg 1998; 87: 319-23.

42 Andersen $G$, Rasmussen H, Rosenstock C, et al. Postoperative pain control by epidural analgesia after transabdominal surgery. Efficacy and problems encountered in daily routine. Acta Anaesthesiol Scand 2000; 44: 296-301.

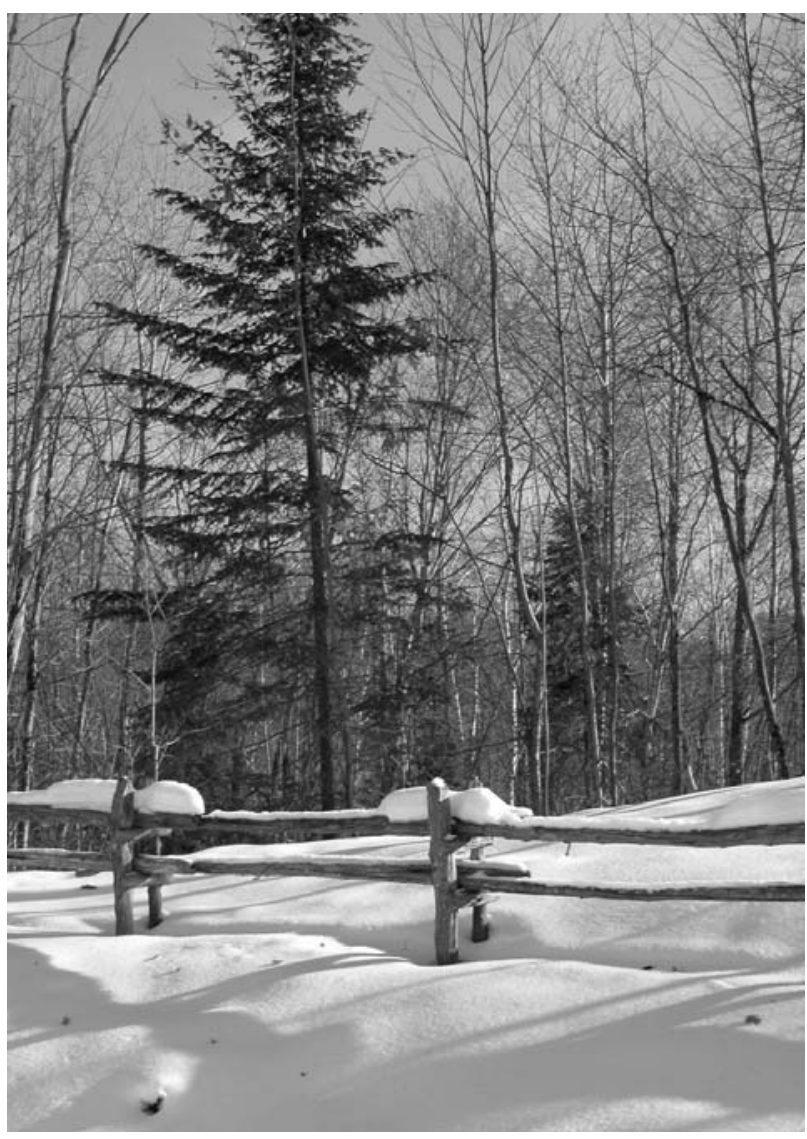

After the Storm - Quebec, Canada 